\title{
DNA methylation of pck1 might contribute to the programming effects of early high-carbohydrate diets feeding to the glucose metabolism across two generations in zebrafish (Danio rerio)
}

\section{Tong Liu}

Huazhong Agriculture University

Xu-Fang Liang ( $\nabla$ xufang_liang@hotmail.com )

College of fisheries of Huazhong Agricultural University

Wenjing Cai

Huazhong Agriculture University

Wuyuan Zhuang

Huazhong Agriculture University

Yanpeng Zhang

Huazhong Agriculture University

\section{Research Article}

Keywords: High-carbohydrate diets programming, Glucose metabolism, DNA methylation, Intergenerational inheritance

Posted Date: January 31st, 2022

DOI: https://doi.org/10.21203/rs.3.rs-1272056/v1

License: (c) (i) This work is licensed under a Creative Commons Attribution 4.0 International License.

Read Full License 


\section{Abstract}

To assess the effects of early high-carbohydrate stimulus on glucose metabolism across two generations in zebrafish (Danio rerio) and explore a mechanism to explain those nutritional programming effects via epigenetic modification. The larvae were delivered a high-carbohydrate diet (53.66\%) during first-feeding to the end of the yolk-sac (FF) and after yolk-sac exhaustion for $5 \mathrm{~d}(\mathrm{YE})$ as early nutritional stimulus. Then those larvae (F0) and their offspring (F1) were both fed with control diet (22.69\%) until adult (15 week), they were challenged with a high-carbohydrate diet (35.36\%) at 16th week. The results indicated that early stimulus raised the mRNA levels of genes involved in glycolysis and gluconeogenesis immediately. At the end of challenge in F0, the plasma glucose levels were decreased and expression levels of glucokinase ( $g c k$ ) were increased, the transcription of genes in gluconeogenesis were inhibited in two treatment groups. When challenged in $\mathrm{F} 1$, the glucose levels were lower in FF (F1) and the mRNA levels of phosphoenolpyruvate carboxykinase 1 (pck1) were decreased in FF (F1), YE (F1). Besides, the lower expression levels corresponding with hypermethylation in $\mathrm{CpG}$ island of $p c k 1$ were maintained from the adult of F0, 24 hours post-fertilization embryo to the adult of F1 in two experimental groups (F0 and F1). In conclusion, these results indicated that early high-carbohydrate stimulus could significantly reprogram glucose metabolism in adult zebrafish and those modifications could be transmitted to next generation partly, the DNA methylation of $p c k 1$ might work as a stable epigenetic marker to contribute to those processes.

\section{Introduction}

In mammals models, it is widely accepted that nutritional perturbations at crucial developmental windows, such as fetal or postnatal stage, could permanently program metabolism and elicit lifelong effects on organism's physiology and metabolism, which was known as nutritional programming (Patel et al., 2009; Ruchat et al., 2014). The early nutritional interferences are believed to confer the adaptive advantages to the animals which could promote them to sustain themself better when the nutritional environment in later life corresponds with that experienced in early stages(K. A. Lillycrop \& Burdge, 2012; Marousez et al., 2019; Zheng et al., 2014). Those changes of physiology and metabolism were often accompanied by the changes in protein or mRNA levels or even the epigenetic changes in DNA methylation or histone modifications at promoter regions of candidate genes (K. Lillycrop \& Burdge, 2015; Patel et al., 2009; Randunu \& Bertolo, 2020; Ruchat et al., 2014). And sometimes those modifications could be transmitted to future generations as show by the research in Dutch famine about the nutritional programming induced by starvation during World War II (Roseboom et al., 2011). Fish are traditionally considered to be glucose intolerant and have limited ability to digest, absorb and metabolize carbohydrates in diets, especially the carnivorous species (Kamalam et al., 2017; Wilson, 1994). However, there is now substantial evidences that the ability of carbohydrate utilization in fish could be modified through nutritional programming. Fang et al. (2013) found that the adult zebrafish which were fed with a high-carbohydrate diet during the first-feeding period showed a lower plasma glucose levels and altered expression and activity levels of enzymes involved in carbohydrate digestion, transport and metabolism 
when challenged with a similar high-carbohydrate diet in adult. Glucose injection in the yolk (early stimulus) induced the enhancement of glycolysis and glucose catabolism, the inhibition of gluconeogenesis in zebrafish juveniles (Rocha et al., 2015). The adult Gilthead seabream (Sparas aurata) which were briefly exposed to a high-glucose feeding at larval stage showed higher catabolism and lower retention of glucose, and higher bio-conversion of glucose into lipids in tissues when challenged with a similar diet (Rocha et al., 2016a; Rocha et al., 2016b). In conclusion, in fish, although many studies reveled the programming effects of early high-carbohydrate/high-glucose stimulus on the glucose metabolism in later life, the mechanism behind those phenomenon and whether those effects could be inherited by the offspring were still unclear.

Discussions on the mechanisms of programming have been ongoing since the 1990s, yet they remain largely unknown. Among many mechanisms, epigenetic modification especially DNA methylation had been identified as one of the most important (K. A. Lillycrop \& Burdge, 2012; McGee et al., 2018; Zheng et al., 2014). DNA methylation occurs predominantly at the $C p G$ dinucleotide and the hypermethylation in the $\mathrm{CpG}$ island (CpG-rich clusters) were usually associated with transcription suppression (Jones, 2012; Wilkinson, 2015). In mammals, a series of studies have demonstrated that the nutrition environment in the crucial developmental windows could trigger the DNA methylation modification. The increased consumption of fish oil during gestation and lactation in rats (Rattus norvegicus) would induce the higher DNA methylation levels in the promoter region of fatty acid desaturase 2 (FADS2) gene in the liver of offspring, which decreased the expression levels of fads 2 and lead to a lower levels of arachidonic acid and docosahexaenoic acid (Hoile et al., 2013). Compared with the rats fed with milk-like high-fat formula since they were born, the DNA methylation and histone in Neuropeptide Y (NPY) gene proximal promoter and histone acetylation in pre-pro-opiomelanocortin (POMC) gene promoter were modified in rats fed with high carbohydrate milk formula whether in pups or adult, which might develop early and persistent hyperinsulinemia as well as post-weaning hyperphagia, adult onset obesity (Mahmood et al., 2013; Srinivasan et al., 2003; Srinivasan et al., 2008). Besides, the nutrition perturbations during key ontogenetic phase were considered to induce lifelong effects not only on the current generation, but also on the future descendants. Burdge et al. (2007) found that the dietary protein restriction of pregnant rats in the F0 generation induces altered methylation of hepatic gene promoters in the adult male offspring in the F1 and F2 generations despite that dietary protein restriction was only applied in F0 generation and no dietary modification was administered in their offspring. Wei et al. (2014) revealed that prediabetes could be inherited transgenerationally through the mammalian germ line by DNA methylation.

In Summary, epigenetic mechanisms provided a compelling explanation for nutritionally programmed metabolic syndrome and the intergenerational inheritance effects in mammals, however evidences of the epigenetic mechanisms being associated with nutritional programming in fishes are still scarce (Hou \& Fuiman, 2020).

Therefore, in the present study, the plasma glucose levels and key gene expression levels in glycolysis and gluconeogenesis were measured in adult zebrafish of F0 and F1 at the end of the challenge to illustrate the intergenerational effects of early high-carbohydrate stimulus. Further, we evaluated the DNA 
methylation statue of phosphoenolpyruvate carboxykinase 1 ( $p c k 1)$ in two generations of the fish to explore the role of epigenetics might played in early high-carbohydrate programing. Our results could promote the understanding to the early high-carbohydrate programming effects on glucose metabolism and provide references to the studies about the mechanism of early nutritional programming in fish, especially in glucose metabolism.

\section{Materials And Methods}

\section{Diets preparation and feeding regime}

Three experimental diets were prepared in the present study and they are prepared in Huazhong Agricultural University (Wuhan, China). All the ingredients (obtained from Gao Long Dietary Company, Wuhan, China) were ground into a fine powder through a $180 \mu \mathrm{m}$ mesh and mixed the ingredients with fish oil and water to get the compound. The compound was put into the screw extruder (Nuoda, Xingtai, China) and got the pellets, then dried for about $12 \mathrm{~h}$ at $25^{\circ} \mathrm{C}$ and broken up, sieved into a proper size and stored at $-20^{\circ} \mathrm{C}$ until use. The ingredient formulation and the proximate chemical composition of the experimental diets were shown in Table 1.

During the two early developmental stages, first-feeding to the end of the yolk-sac larval (3-5 days posthatching (dph), FF) and after yolk-sac exhaustion for $5 \mathrm{~d}$ (6-10 days post-hatching (dph), YE), the larvae of experimental groups were fed HS diet (53.66\% carbohydrate and $25.84 \%$ protein) and the control group were fed control diet (20.53\% carbohydrate and $53.11 \%$ protein). Then all three groups (FF, YE and control group, defined as F0) were fed with the control diet until the adult (15 week). At last, a HC (35.36\% carbohydrate and $43.40 \%$ protein) diet was given to the adult fish in all groups at 16 th week as a challenge test (Hou \& Fuiman, 2020). The next generation of the three groups were defined as F1, were fed the control diet ( $20.53 \%$ carbohydrate and $53.11 \%$ protein) until the adulthood ( 15 week), then replaced the control diet for a $\mathrm{HC}$ diet (35.36\% carbohydrate and $43.40 \%$ protein) for one week as the challenge test. The feeding schemes were summarized in Table 2.

\section{Fish rearing and breeding}

The embryos of the wild-type zebrafish were obtained from the Institute of Hydrobiology, Chinese Academy of Sciences (Wuhan, China). The embryos were randomly divided into three groups and hatched in College of Fisheries, Huazhong Agricultural University (Wuhan, China). The larvae were reared in a filtered recirculating culture system $10 \mathrm{~d}$ after hatching. Six tanks $(10 \mathrm{~L})$ were randomly prepared for FF, YE and control group respectively. 100 fish lived in a tank, one month later, half of the fish in a tank were transferred into another tank. During the high-carbohydrate diet stimulus period, the larvae were fed six times to visual satiety from 8:00 to 19:00 daily, then the fish were fed two times at 8:30 and 18:30 daily until 16 week (include the challenge test period) (Fang et al., 2013).

The sexual maturity adult zebrafish ( 15 week) which were selected from each group were transferred to breeding tanks before the onset of darkness. On the next morning, after exposed to light for 20-30 min, 
the eggs were collected from the spawning trays which was on the bottom of the breeding tanks and transferred to Petri dishes ( $90 \mathrm{~mm}$ in diameter, 50 eggs/dish) (Santangeli et al., 2019). The embryos were incubated at $28^{\circ} \mathrm{C}$ and the larvae were transferred into a filtered recirculating culture system $10 \mathrm{~d}$ after hatching. The fish were fed two times at 8:30 and 18:30 daily from the first-feeding to the challenge test. All zebrafish were kept at $28 \pm 1^{\circ} \mathrm{C}$ and $\mathrm{PH}$ at $7.50-7.73$ under a $14 \mathrm{~h} / 10 \mathrm{~h}$ light/dark cycle.

\section{Sampling}

At the end of the early high-carbohydrate stimulus ( $5 \mathrm{dph}$ and $10 \mathrm{dph}$ ), the average body weight ( $\mathrm{n}=6$ samples of 15 larvae each) and body length (performed by an Olympus LG-SP2 stereoscopic microscope, SZX2-FOF 9J01021, $\mathrm{n}=6$ samples of 15 larvae each) of treatment and control group were calculated. For the molecular analyses, the whole bodies of larvae ( $n=6$ samples of 15 larvae each) in each group were quickly frozen in liquid $\mathrm{N}_{2}$ and stored in $-80^{\circ} \mathrm{C}$.

For the adult fish ( 15 week) of F0 and F1, six zebrafish in each group were randomly chosen and deeply anesthetized with MS-222 (Redmond, WA, USA, $200 \mathrm{mg} / \mathrm{L}$ ) ( $3 \mathrm{~h}$ after the last meal), the body weight and length were recorded and the blood were collected at the caudal vein to evaluate the plasma glucose levels with the Glucose Assay Kit (Catalog no. F006-1-1, Jiancheng Institute of Biotechnology, Nanjing, China). Given that the liver plays a central role in the production and catabolism of glucose in response to nutrition conditions to keep glucose homeostasis in fish (Enes et al., 2009; Hao et al., 2015), so it was chose for molecular analyses. The liver was quickly frozen in liquid $\mathrm{N}_{2}$ and stored at $-80^{\circ} \mathrm{C}$. At the end of $\mathrm{HC}$ diet challenge ( 16 week) in F0 and F1. Six fish in each group were randomly sampled ( $3 \mathrm{~h}$ after the last meal), the way to collect the blood and liver just like previous described.

DNA demethylation in zebrafish embryos begins at nearly 24 hours post- fertilization (hpf) (Bogdanović et al., 2016) and the peak in glucose also occurred almost at this time (Jurczyk et al., 2011), so at the end of $24 \mathrm{hpf}$, the embryos ( $\mathrm{n}=6$ samples 40 embryos each) were frozen in liquid $\mathrm{N}_{2}$ and stored at $-80{ }^{\circ} \mathrm{C}$ for DNA or RNA extraction in each group.

\section{Real-time quantitative PCR}

The isolation of total RNA was performed with Trizol Reagent (TaKaRa, Tokyo, Japan) following the manufacturer's instructions. The BioTek Synergy 2 luminometer (BioTek, Winooski, VT, USA) was used to evaluate the RNA concentration and quantity. The electrophoresis in $2 \%$ agarose gel (Biowest Agarose, Madrid, Spain) was used to assess the integrity of total RNA. The transcription of total RNA to cDNA was performed with Revert Aid ${ }^{\text {TM }}$ Reverse Transcriptase (TaKaRa, Tokyo, Japan) according to the manual. The real-time quantitative polymerase chain reaction were performed with $\mathrm{MyiQ}^{\mathrm{TM}} 2$ Two-Color Real-Time PCR Detection System (BIO-RAD, Hercules, CA, USA) as the methods described by Fang et al (Fang et al., 2013). The primes for RT-qPCR were designed by Primer Premier 5.0 software and were listed in Table 3 . $\beta$-actin gene was selected as the reference for the stable expression in zebrafish (Peng \& Ge, 2000). The mRNA levels of target genes relative to $\beta$-actin gene were calculated by the optimized comparative $\mathrm{Ct}(2-$ 
$\Delta \Delta C$ t) value method (Livak \& Schmittgen, 2002). Data with six biological replicates and three technical replicates were presented as mean \pm S.E.M.

\section{DNA methylation analysis}

The gene sequences were submitted to the online software MethPrimer (http://www.urogene.org/cgi$\mathrm{bin} /$ methprimer/methprimer.cgi) to get the distribution of $\mathrm{CpG}$ islands (CGIs) and the candidate CpG loci, the parameters were as follows: Island size $>100 \mathrm{bp}, \mathrm{GC}$ Percent $>50.0 \%$, Observed/Expected $>0.6$. Given that no $\mathrm{CpG}$ islands were found for $g c k, p k$ and $f b p 1 b$, and in terms of gene expression, only $p c k 1$ expression levels were significantly changed in both two experimental groups across two generations after the challenge test. So $p c k 1$ was chosen as the candidate gene for DNA methylation analysis. The BSP primers were designed by the online software MethPrimer and Primer Premier 5.0 (Table 4).

The genomic DNA were isolated with TIANamp Genomic DNA Kit (Tiangen, Beijing, China) following the standard procedures. The genomic DNA was treated with the EZ DNA Methylation Kit (Zymo Research, Irvine, CA, USA) according to the manufacturer's protocol. The polymerase chain reaction (PCR) was performed by Taq plus DNA Polymerase (Vazyme Biotech, Nanjing, China) in Biometra Thermo cyclers (Biometra, Göttingen, Germany). The PCR products were purified by the Gel Purification Kit (Sangon, Shanghai, China) and then the products were transformed to the pEASY-T1 Cloning kit (Transgen, Beijing, China). Five positive clones were randomly obtained from each sample and sequenced in Sangon Biotech (Shanghai) Co., Ltd (ABI3730, Applied Biosystems) and there were 30 positive clones for each group. The sequencing results were processed by online QUMA (Quantification tool for Methylation Analysis) software (http://quma.cdb.riken.jp/).

\section{Statistical analysis}

Date were expressed as means \pm S.E.M. Statistical analysis was performed by SPSS 25 software. The normality of data was assessed with the Shapiro-Wilk test. Then all data were analyzed using one-way analysis of variance (ANOVA), followed by Tukey's multiple range tests. If $P<0.05$, differences were considered significant.

\section{Results}

\section{Growth performance and plasma glucose levels}

The growth performance and plasma glucose levels of F0 and F1 were summarized in Table 5. The early HS diet stimulus significantly increased the body weight (calculated with the averaged weight) of the larvae at the end of FF stage (Table 5). However, a reversed result was found at the end of YE stage, a significantly lower body weight was observed in experimental group (Table 5). And the nutrition stimulus did not affect the body length (individual length) in both two experimental groups (Table 5). During the adult (15 week), compared with control group, there is no significant differences in body weight, body length and the plasma glucose levels (BC glucose levels) of both FF and YE groups (Table 6). At the end 
of the challenge ( 16 week), the postprandial blood glucose levels (AC glucose levels) of two experimental groups was both significantly decreased (Table 6).

The next generation of the three groups were fed with control diet until adult ( 15 week). The body weight, length and plasma glucose levels (BC glucose levels) were recorded in Table 7 and there was no differences between three groups. After the challenge test (16th week), the postprandial blood glucose levels (AC glucose levels) of FF (F1) and YE (F1) were lower than that in control group (F1), although there was no significant difference between YE (F1) and control group (F1) (Table 7).

\section{Glycolytic and gluconeogenic gene expression}

The expression levels of $g c k$, fbp $1 a$ and $p c k 1$ were up-regulated at the end of FF period (Fig.1(A)). At the end of YE period, the mRNA levels of $p f k l a, p f k l b$ and $p c k 1$ were significantly increased and the pk expression levels were significantly inhibited (Fig.1(B)). At the end of the challenge in F0, the expression of seven genes which were responsible for glycolysis and gluconeogenesis were detected in the liver of zebrafish. As the first gene to participate in glycolysis progress, gck expression levels were significantly increased in both FF and YE group (Fig.2). In the FF group, the mRNA levels of $p f k l a$ were significantly higher than the levels in control group (Fig.2). For the three key genes in gluconeogenesis, $f b p 1 a, f b p 1 b$ and $p c k 1$ expression levels in two experimental groups were both significantly repressed compared with the control group (Fig.2). At the end of $\mathrm{HC}$ diet challenge test in $\mathrm{F} 1$, the expression levels of $p k$ in FF (F1) were higher than control group (F1) (Fig.3). And compared with control group (F1), the expression levels of $f b p 1 a, f b p 1 b$ were significantly inhibited in YE (F1) group, the mRNA levels of pck1 were both significantly lower in FF (F1) and YE (F1) group (Fig.3).

\section{The intergenerational inheritance of pck1 DNA methylation}

The pck1 expression levels were detected in the liver of F0 adult zebrafish, the $24 \mathrm{hpf}$ embryos of F1 and the liver of F1 adult zebrafish. Compared with the control group, the significantly lower mRNA levels of pck 1 in two experimental groups were found in all three phases (Fig.4). It showed a stable tendency between the two generations. To investigate the possibility that the lower $p c k 1$ expression levels were the result of the changes of the modification of DNA methylation, we analyzed the percent of 5methylcytosine (5-mC) / total cytosine in the $\mathrm{CpG}$ island of $p c k 1$ gene. The sequence before initiation codon for 2500bp were submitted to the online software Methprimer and a CpG island, which located at $-1849 \sim-1656$ bp (Initiation codon ATG is regarded as the ' +1 ' site), was found and the length of the island was $194 \mathrm{bp}$, which contained $17 \mathrm{CpG}$ sites. The analysis of $17 \mathrm{CpG}$ sites found a significantly increased methylation level in the liver of F0, embryos of $24 \mathrm{hpf}$ and liver of F1 in both two experimental groups compared with the control (Fig.5).

\section{Discussion}

zebrafish cannot utilize exogenous food and exclusively depend on the yolk reserves when they are hatching. After the opening of the esophagus, they could ingest the artificial diet (Carvalho et al., 2006). In 
the present study, the HS diet (53.66\% carbohydrate and $25.84 \%$ protein) stimulus significantly increased the body weight of the larvae during the first-feeding period compared with the control group. The results of previous research in zebrafish was in line with our findings. The three days high-carbohydrate diet treatment $(49.46 \%$ carbohydrate and $31.87 \%$ protein) at first feeding stage induced a significantly increased body weight of zebrafish compared with control diet $(20.53 \%$ carbohydrate and $53.11 \%$ protein) feeding (Fang et al., 2013). However, the different responses were reported in Siberian sturgeon (Acipenser baerii) and rainbow trout (Oncorhynchus mykiss). Compared with the control group (fed with the diet containing $3.6 \%$ carbohydrate and $67.7 \%$ protein), the high glucose stimulus diet $(59.8 \%$ carbohydrate and $21.5 \%$ protein) on the beginning of exogenous nutrition stage in Siberian sturgeon significantly repressed the body weight of the larvae (Gong et al., 2015) and the similar results were also found in rainbow trout (Oncorhynchus mykiss) (Geurden et al., 2007). The different response in species might be the result of the differences in the ability to digest and metabolize dietary carbohydrates. When the yolk sac was exhausted, the larvae must live on the exogenous nutrition. However, an reversed tendency in body weight was observed when the fish were fed with same HS diet.

After the high-carbohydrate stimulus, all zebrafish were fed with control diet until 15 week, then the differences in body length and weight were no longer existed between the experimental groups and control group, which indicated that briefly exposed to high-carbohydrate diet at early ontogenetic phases had no negative effects on the health of adult zebrafish. The studies in rainbow trout (Geurden et al., 2007), gilthead seabream (Rocha et al., 2016b) and zebrafish (Fang et al., 2013) also reported the similar results. However, Kumkhong et al. (2020) found that although early high-carbohydrate diet-fed tilapia (Oreochromis niloticus) had poorer growth (end of stimulus), the fish showed compensatory growth and it finally led to the improvement of growth performance in adult fish, which might be the results of the improvement of the ability to use glucose and to induce lipogenesis and the suppression to amino acid catabolism. In Siberian sturgeon, high-glucose diet stimulus during first feeding period disturbed the metabolism and although the fish could apparently adapt to later nutritional conditions by reversing the disturbances in the gluconeogenesis pathway in 20 weeks feeding, the growth performances were still poor (significantly lower body weight) (Gong et al., 2015). In conclusion, there were no consistent responses about the high-glucose/high-carbohydrate stimulus during early ontogenetic phase on adult growth performances in different fish. Besides, we found that there was no differences of the body weight and body length between both two experimental groups and control group in F1 generation, which suggested that the early high-carbohydrate diet stimulus would not affect the growth performances of the next generation in zebrafish.

Although fish have limited ability to use carbohydrates in diet, they have most key enzymes involved in carbohydrate metabolic pathways (Polakof et al., 2012). In fish, glucose is catabolized through the glycolytic pathway or other ways for ATP production. On the contrary, glucose requirements for metabolic purposes could be satisfied by de novo glucose synthesis through gluconeogenesis or other ways (Enes et al., 2009; Stone, 2003; Wilson, 2003). Thus, to maintain glucose homeostasis, a balance between glucose consumption and production which depend on the regulation of activity and expression of key enzymes involved in the glycolysis and gluconeogenesis pathways was critical (Enes et al., 2009). As the 
key gene in glycolysis, $g c k(\mathrm{FF}), p f k l a(\mathrm{YE})$ and $p f k l b(\mathrm{YE})$ gene expression were up-regulated immediately after the larvae experienced the HS diet. Previous researches in fish also found that high-carbohydrate stimulus at early development stages could raise the expression of genes in glycolysis rapidly, such as gck in zebrafish (Fang et al., 2013), gilthead seabream (Rocha et al., 2016b), rainbow trout (Geurden et al., 2007) and European sea bass (Dicentrachus labrax) (Zambonino-Infante et al., 2019), pk in zebrafish (Fang et al., 2013), gilthead seabream (Rocha et al., 2016b) and pfk-lin gilthead seabream (Rocha et al., 2016b). Those results indicated that fish larvae could adapt to the utilization of exogenous glucose in early development stage by the improvement of glucose oxidation. In fact, some scholars believe that there is a closer relationship between carbohydrates and feeding habit than proteins at the early larval stages (Xiang. Fan et al., 2010; Hidalgo et al., 1999; Kapoor et al., 1976). PK catalyzes the last step in the glycolysis process, which is one of the rate-limiting steps in this process. However, the expression levels of $p k$ were decreased in YE group. Previous study in zebrafish larvae also found the reduced mRNA levels when fed with high-carbohydrate diet after the yolk sac was exhausted, however the activities of PK were enhanced, which indicated the possibility of post-transcriptional regulation for pk gene (Fang et al., 2013). At the end of FF stage, the mRNA levels of $f b p 1 a$ and $p c k 1$ were up-regulated, the catabolism of the vitelline reserves might contribute to this (Fang et al., 2013). Interesting, the higher transcription levels of $p c k 1$ were observed in YE group. Which might increase the production of endogenous glucose and diminish appetite to avoid the excessive intake of feed for the larvae. The significantly lower body weight in YE group was one of the evidences.

In the 1990s, professor Barker and Hales proposed that nutrition during early life could permanently change the phenotype along with ageing, such as impaired glucose metabolism, which was known as 'fetal programming hypothesis' (Hales et al., 1991). According to this hypothesis, underwent the special nutrition environment in the early ontogenetic phases could bring animals the adaptive advantages, and those advantages could promote them to behave better in later life, especially when they encountered the similar environment. The results of present study were in agreement with that. In the present study, after the high-carbohydrate treatment in the larvae, all fish were fed with control diet until adult and a $\mathrm{HC}$ diet was used to test the ability of fish to utilize carbohydrate in diet (Hou \& Fuiman, 2020). At the end of the challenge, the plasma glucose levels in two experimental groups were both significantly decreased compared with the control group. For genes which were responsible for glycolysis, the transcription of gck were enhanced in FF and YE group, and pfkla mRNA levels were higher in FF group. The key genes transcription levels in gluconeogenesis including $f b p 1 a, f b p 1 b, p c k 1$ were all significantly decreased in two treatment groups compared with control group. Those results indicated high-carbohydrate diet in zebrafish larvae might improve the utilization of carbohydrate in diet in adult thought the improvement of the glucose uptake and phosphorylation levels and the decrement of endogenous glucose production. In fish, many studies had showed that early high-carbohydrate/high-glucose diet could significantly affect the carbohydrate metabolism in later life. Gilthead seabream that experienced glucose-rich feed during the larval stage had a higher catabolism and lower glucose retention in tissues and the hepatic lipogenesis were enhanced when challenged with a high-carbohydrate diet in post-larval stage (Rocha et al., 2016a; Rocha et al., 2016b). The plasma glucose levels, mRNA levels and enzyme activity levels of 
pck1 were all decreased in the adult zebrafish that had received high-carbohydrate diet at first-feeding period when challenged with a high-carbohydrate diet (Fang et al., 2013). However, the similar researches in rainbow trout, Siberian sturgeon and European sea bass showed different responses including absence of, or opposite changes in glucose homeostasis (unaltered or higher plasma glucose levels) and/or expression of some genes related to carbohydrate metabolism (Geurden et al., 2007; Gong et al., 2015; Zambonino-Infante et al., 2019). To sum up, the programming effects of high-carbohydrate diet at early development stages on carbohydrate metabolism in fish were not always consistent.

In mammal models, studies had pointed that nutrition intervention during the crucial developmental windows in parents especially in maternal line had a great influence on the carbohydrate metabolism in future generation. The rat whose mother had a protein restriction diet during pregnancy showed a decreased activities of glucokinase and an increased phosphoenolpyruvate carboxykinase activities during the weaning and adult (Desai et al., 1995). And the altered physical structure and function of the liver in the offspring might be responsible for those results (Desai et al., 1995). Prenatal protein restriction was associated with reduced pancreatic GK activity in 3-month-old rat offspring (Hales et al., 1996). And the blood glucose levels in those rat were higher when they were injected with glucose, which means a poorer glucose tolerance in those rats (Hales et al., 1996). In the present study, we also found the programming effects of early high-carbohydrate on the offspring of the experimental groups. The offspring of three groups were all fed with control diet until adult. After the HC diet challenge, compared with control group (F1), the postprandial blood glucose level in the offspring of two treatment groups were all decreased, although there was no difference between FF (F1) and control group (F1). Besides, the transcription levels of $p k$ were raised in FF (F1) and the mRNA levels of $f b p 1 a$ and $f b p 1 b$ were all lower in YE (F1), the pck1 expression were inhibited in both FF (F1) and YE (F1). Those results indicated that early high-carbohydrate stimulus could affect the glucose metabolism in zebrafish until the next generation. And compared with stimulus after yolk-sac exhaustion, nutritional programming in first-feeding period might be more potential to transmit the effects of early high-carbohydrate programing to next generation.

To explore the possible mechanism for the nutritional programming effects, we analyze the DNA methylation levels of $p c k 1$ in two generations of zebrafish cause of the finds that $p c k 1$ gene expression levels were inhibited in experimental groups in both F0 and F1 adult at the end of the challenge test. DNA methylation is a common and stable epigenetic modification in animal genomes. It could stably regulate genes expression and transmit through DNA replication as cells divide and differentiate from embryonic stem cells into specific tissues (Bird, 2002). The heritable cytosine methylation primarily occurs in the context of the symmetric $\mathrm{CpG}$ dinucleotide, where replication results in two daughter genomes each carrying a hemimethylated $\mathrm{CpG}$ that provides a substrate for the maintenance methyltransferase (Bošković \& Rando, 2018). And the CpG methylation patterns are largely erased from one organismal generation to the next. However, in zebrafish, some researches had reported that the inheritance of some DNA methylation patterns could be intergenerational even transgenerational inheritance (Xiaoteng Fan et al., 2019; Kamstra et al., 2018; Olsvik et al., 2014; Santangeli et al., 2019). In zebrafish, the DNA methylation model is reset almost immediately after fertilization (Mhanni \& McGowan, 2004) and subsequent de novo methylation occurs (MacKay et al., 2007; Mhanni \& McGowan, 2004) after which 
sperm DNA becomes hypermethylated compared with oocyte DNA in newly fertilized embryos (Mhanni \& McGowan, 2004). Paternal methylation patterns are retained through early development, but maternal methylation patterns are lost by the midblastula stage and altered to resemble paternal methylation patterns (Jiang et al., 2013; Potok et al., 2013). The early developmental methylation landscapes indicated that DNA methylation might serve as a conduit for parental effects in zebrafish (Perez \& Lehner, 2019). PEPCK-C, which was encoded by $p c k 1$ in zebrafish, could convert oxaloacetate into phosphoenolpyruvate and carbon dioxide which was a rate-limiting step of gluconeogenesis in the liver. As a non-allosteric enzyme, the transcription level is the primary controller of enzyme activity as the lack of post-transcriptional regulation (Li et al., 2019). Besides, the studies in mice and fish both pointed that the over-expression of liver $p c k 1$ expression led to hyperglycemia, hyperinsulinemia, and altered hepatic glycogen contents (Valera et al., 1994). In the present study, the lower plasma glucose levels were detected in the adult of F0 (15 week) and F1 (15 week), although there was no significant differences. Then, we found that the significantly lower transcription levels of $p c k 1$ existed in the two experimental groups of adult F0, 24 hpf embryos and adult F1, corresponding with significantly higher global DNA methylation levels (the percent of 5-methylcytosine (5-mC)/total cytosine) in the $\mathrm{CpG}$ island. Those results revealed that $p c k 1$ might be the adaptive gene, which was programmed by high-carbohydrate diet in two early stages and it persisted in the subsequent generation, which might enable future generations to maintain glucose homeostasis. Besides, we found that not all the changes of genes transcription could be transmitted to the next generation, such as the $g c k$, fbp $1 a$ and $f b p 1 b$, the transcription levels of those genes were all effected in two treatment groups of F0, however the differences were no longer existed in F1 generation.

In conclusion, the present study suggested that early high-carbohydrate diet stimulus could enhance the glycolysis process and reduce endogenous glucose production by regulating the key genes expression until the adult in zebrafish and those effects could be delivered to next generation partly. The DNA methylation of $p c k 1$ might be the possible transmission pathway to deliver the $p c k 1$ expression model from F0 to F1. Our results could promote the research to the role of DNA methylation played in nutrition programming and provide a novel route to understand the possible mechanisms of nutrition programming, further, to improve the study and application of nutrition programming to aquaculture and fisheries, with regard to glucose metabolism.

\section{Declarations}

\section{Funding}

This work was supported by National Key R\&D Program of China (2018YFD0900400), China Agriculture Research System (CARS-46) and the National Natural Science Foundation of China (31972809).

\section{Conflicts of interest}

The authors declare that they have no competing interests. The founding sponsors had no role in the design of the study; in the collection, analyses, or interpretation of data; in the writing of the manuscript, 
and in the decision to publish the results.

\section{Ethics approval}

All the fish and experiments were conducted according to the "Guidelines for Experimental Animals" published by Ministry of Science and Technology (Beijing, China). This study had been approved by the Institutional Animal Care and Use Ethics Committee of Huazhong Agricultural University.

Consent to participate Not applicable.

Consent to publication Not applicable.

\section{Data Availability}

All data are available from the corresponding author by request. The authors declare that they have no known competing financial interests or personal relationships that could have appeared to influence the work reported in this paper.

\section{Author contribution}

Xu-Fang Liang and Wenjing Cai conceived and designed the experiments; Tong Liu and Wuyuan Zhuang performed the experiments; Tong Liu, Xu-Fang Liang, Wenjing Cai and Yanpeng Zhang wrote and revised the manuscript. All authors read and approved the final manuscript.

\section{References}

1. Beale EG, Harvey BJ, Forest C (2007) PCK1 and PCK2 as candidate diabetes and obesity genes. Cell Biochem Biophys 48(2):89-95. http://doi.org/10.1007/s12013-007-0025-6

2. Bird A (2002) DNA methylation patterns and epigenetic memory. Genes Dev 16:6-21

3. Bogdanović O, Smits AH, de la Calle Mustienes E, Tena JJ, Ford E, Williams R, Lister R (2016) Active DNA demethylation at enhancers during the vertebrate phylotypic period. Nat Genet 48(4):417-426. http://doi.org/10.1038/ng.3522

4. Bošković A, Rando OJ (2018) Transgenerational Epigenetic Inheritance. Annu Rev Genet 52:21-41. http://doi.org/10.1146/annurev-genet-120417-031404

5. Burdge GC, Slater-Jefferies J, Torrens C, Phillips ES, Hanson MA, Lillycrop KA (2007) Dietary protein restriction of pregnant rats in the $\mathrm{FO}$ generation induces altered methylation of hepatic gene promoters in the adult male offspring in the F1 and F2 generations. Br J Nutr 97(3):435-439. http://doi.org/10.1017/s0007114507352392

6. Carvalho AP, Araújo L, Santos MM (2006) Rearing zebrafish (Danio rerio) larvae without live food: evaluation of a commercial, a practical and a purified starter diet on larval performance. Aquac Res 37(11):1107-1111 
7. Desai M, Crowther NJ, Ozanne SE, Lucas A, Hales CN (1995) Adult glucose and lipid metabolism may be programmed during fetal life. Biochem Soc Trans 23:331-335. http://doi.org/10.1042/bst0230331

8. Enes P, Panserat S, Kaushik S, Oliva-Teles A (2009) Nutritional regulation of hepatic glucose metabolism in fish. Fish Physiol Biochem 35(3):519-539. http://doi.org/10.1007/s10695-008-92595

9. Fan X, Hou T, Sun T, Zhu L, Zhang S, Tang K, Wang Z (2019) Starvation stress affects the maternal development and larval fitness in zebrafish (Danio rerio). Sci Total Environ 695:133897. http://doi.org/10.1016/j.scitotenv.2019.133897

10. Fan X, Klein M, Flanagan-Steet HR, Steet R (2010) Selective yolk deposition and mannose phosphorylation of lysosomal glycosidases in zebrafish. J Biol Chem 285(43):32946-32953

11. Fang L, Liang X-F, Zhou Y, Guo X-Z, He Y, Yi T-L, Tao Y-X (2013) Programming effects of highcarbohydrate feeding of larvae on adult glucose metabolism in zebrafish, Danio rerio. Br J Nutr 111:1-11. http://doi.org/10.1017/S0007114513003243

12. Geurden I, Aramendi M, Zambonino-Infante J, Panserat S (2007) Early feeding of carnivorous rainbow trout (Oncorhynchus mykiss) with a hyperglucidic diet during a short period: Effect on dietary glucose utilization in juveniles. Am J Physiol Regul Integr Comp Physiol 292:R2275-2283. http://doi.org/10.1152/ajpregu.00444.2006

13. Gong G, Xue M, Wang J, Wu X-f, Zheng Y-h, Han F, Su X-o (2015) The regulation of gluconeogenesis in the Siberian sturgeon (Acipenser baerii) affected later in life by a short-term high-glucose programming during early life. Aquaculture 436:127-136. http://doi.org/https://doi.org/10.1016/j.aquaculture.2014.10.044

14. Hales CN, Barker DJP, Clark PMS, Cox LJ, Fall C, Osmond C, Winter PD (1991) Fetal and infant growth and impaired glucose tolerance. BMJ 303:1019-1022. http://doi.org/10.1136/bmj.303.6815.1474-a

15. Hales CN, Desai M, Ozanne SE, Crowther NJ (1996) Fishing in the Stream of Diabetes: From Measuring Insulin to the Control of Fetal Organogenesis. Biochem Soc Trans 24:341-350. http://doi.org/10.1042/bst0240341

16. Hao L, Li SJ, Bai JJ (2015) Research Advances in Gene Regulation and Genetic Improvement of Fish Feeding. Agricultural Science \& Technology 16:2272-2282. http://doi.org/10.16175/j.cnki.10094229.2015.10.045

17. Hidalgo M, Urea E, Sanz A (1999) Comparative study of digestive enzymes in fish with different nutritional habits. Proteolytic and amylase activities. Aquaculture 170(3-4):267-283

18. Hoile SP, Irvine NA, Kelsall CJ, Sibbons C, Feunteun A, Collister A, Burdge GC (2013) Maternal fat intake in rats alters 20:4n-6 and 22:6n-3 status and the epigenetic regulation of Fads2 in offspring liver. J Nutr Biochem 24(7):1213-1220. http://doi.org/https://doi.org/10.1016/j.jnutbio.2012.09.005

19. Hou Z, Fuiman LA (2020) Nutritional programming in fishes: insights from mammalian studies. Rev Fish Biol Fish 30(1):67-92. http://doi.org/10.1007/s11160-019-09590-y 
20. Jiang L, Zhang J, Wang J-J, Wang L, Zhang L, Li G, Liu J (2013) Sperm, but Not Oocyte, DNA Methylome Is Inherited by Zebrafish Early Embryos. Cell 153.

http://doi.org/10.1016/j.cell.2013.04.041

21. Jones PA (2012) Functions of DNA methylation: islands, start sites, gene bodies and beyond. Nat Rev Genet 13:484-492. http://doi.org/10.1038/nrg3230

22. Jurczyk A, Roy N, Bajwa R, Gut P, Lipson K, Yang C, dilorio P (2011) Dynamic glucoregulation and mammalian-like responses to metabolic and developmental disruption in zebrafish. Gen Comp Endocrinol 170(2):334-345. http://doi.org/https://doi.org/10.1016/j.ygcen.2010.10.010

23. Kamalam BS, Medale F, Panserat S (2017) Utilisation of dietary carbohydrates in farmed fishes: new insights on influencing factors, biological limitations and future strategies. Aquaculture 467:3-27

24. Kamstra JH, Hurem S, Martin LM, Lindeman LC, Legler J, Oughton D, Aleström P (2018) lonizing radiation induces transgenerational effects of DNA methylation in zebrafish. Sci Rep 8(1):15373. http://doi.org/10.1038/s41598-018-33817-w

25. Kapoor BG, Smit H, Verighina I (1976) The alimentary canal and digestion in teleosts. Adv Mar Biol 13:109-239

26. Kumkhong S, Marandel L, Plagnes-Juan E, Veron V, Panserat S, Boonanuntanasarn S (2020) Early feeding with hyperglucidic diet during fry stage exerts long-term positive effects on nutrient metabolism and growth performance in adult tilapia (Oreochromis niloticus).Journal of Nutritional Science, 9

27. Li RX, Liu HY, Li SY, Tan BP, Dong XH, Chi SY, Chen LQ (2019) Nutritional regulation of gene expression and enzyme activity of phosphoenolpyruvate carboxykinase in the hepatic gluconeogenesis pathway in golden pompano (Trachinotus ovatus). Aquac Res 50(2):634-643. http://doi.org/10.1111/are.13941

28. Lillycrop K, Burdge GC (2015) Maternal diet as a modifier of offspring epigenetics. Journal of developmental origins of health and disease 6:88-95. http://doi.org/10.1017/S2040174415000124

29. Lillycrop KA, Burdge GC (2012) Epigenetic mechanisms linking early nutrition to long term health. CLINICAL ENDOCRINOLOGY AND METABOLISM 26(5):667-676

30. Livak KJ, Schmittgen TD (2002) Analysis of Relative Gene Expression Data using Real-Time Quantitative PCR. Methods 25(4):402-408

31. Mackay A, Mhanni A, McGowan R, Krone P (2007) Immunological detection of changes in genomic DNA methylation during early zebrafish development. Genome / National Research Council Canada = Génome $/$ Conseil national de recherches Canada 50:778-785. http://doi.org/10.1139/g07-055

32. Mahmood S, Smiraglia D, Srinivasan M, Patel MJ (2013) J. o. d. o. o. h., \& disease. Epigenetic changes in hypothalamic appetite regulatory genes may underlie the developmental programming for obesity in rat neonates subjected to a high-carbohydrate dietary modification. 4(6), 479-490

33. Marousez L, Lesage J, Eberlé D (2019) Epigenetics: Linking Early Postnatal Nutrition to Obesity Programming? Nutrients 11(12):2966 
34. McGee M, Bainbridge S, Fontaine-Bisson B (2018) A crucial role for maternal dietary methyl donor intake in epigenetic programming and fetal growth outcomes. Nutr Rev 76(6):469-478. http://doi.org/10.1093/nutrit/nuy006

35. Mhanni AA, McGowan RA (2004) Global changes in genomic methylation levels during early development of the zebrafish embryo. Dev Genes Evol 214(8):412-417. http://doi.org/10.1007/s00427-004-0418-0

36. Olsvik P, Williams T, Tung H-S, Mirbahai L, Sanden M, Skjærven K, Ellingsen S (2014) Impacts of TCDD and MeHg on DNA methylation in zebrafish (Danio rerio) across two generations. Comparative biochemistry and physiology Toxicology \& pharmacology: CBP 165. http://doi.org/10.1016/j.cbpc.2014.05.004

37. Patel MS, Srinivasan M, Laychock SG (2009) Metabolic programming: Role of nutrition in the immediate postnatal life. J Inherit Metab Dis 32(2):218-228. http://doi.org/10.1007/s10545-008$1033-4$

38. Peng Y, Ge W (2000) Gonadotropin and activin enhance maturational competence of oocytes in the zebrafish (Danio rerio). Biol Reprod 66:259-265

39. Perez MF, Lehner B (2019) Intergenerational and transgenerational epigenetic inheritance in animals. Nat Cell Biol 21(2):143-151. http://doi.org/10.1038/s41556-018-0242-9

40. Polakof S, Panserat S, Soengas J, Moon T (2012) Glucose metabolism in fish: A review. Journal of comparative physiology. B, Biochemical, systemic, and environmental physiology, 182. http://doi.org/10.1007/s00360-012-0658-7

41. Potok ME, Nix DA, Parnell TJ, Cairns BR (2013) Reprogramming the Maternal Zebrafish Genome after Fertilization to Match the Paternal Methylation Pattern. Cell 153(4):759-772. http://doi.org/https://doi.org/10.1016/j.cell.2013.04.030

42. Randunu R, Bertolo R (2020) The Effects of Maternal and Postnatal Dietary Methyl Nutrients on Epigenetic Changes that Lead to Non-Communicable Diseases in Adulthood. Int J Mol Sci 21:3290. http://doi.org/10.3390/ijms21093290

43. Rocha F, Dias J, Engrola S, Gavaia P, Geurden I, Dinis MT, Panserat S (2015) Glucose metabolism and gene expression in juvenile zebrafish (Danio rerio) challenged with a high carbohydrate diet: effects of an acute glucose stimulus during late embryonic life. Br J Nutr 113(3):403-413. http://doi.org/10.1017/S0007114514003869

44. Rocha F, Dias J, Geurden I, Dinis MT, Panserat S, Engrola S (2016a) Dietary glucose stimulus at larval stage modifies the carbohydrate metabolic pathway in gilthead seabream (Sparus aurata) juveniles: An in vivo approach using 14C-starch. Comp Biochem Physiol A: Mol Integr Physiol 201:189-199. http://doi.org/https://doi.org/10.1016/j.cbpa.2016.07.016

45. Rocha F, Dias J, Geurden I, Dinis MT, Panserat S, Engrola S (2016b) High-glucose feeding of gilthead seabream (Sparus aurata) larvae: Effects on molecular and metabolic pathways. Aquaculture 451:241-253. http://doi.org/https://doi.org/10.1016/j.aquaculture.2015.09.015 
46. Roseboom TJ, Painter RC, van Abeelen AF, Veenendaal MV, de Rooij SRJM (2011) Hungry in the womb: what are the consequences? Lessons from the Dutch famine.. 70:141-1452

47. Ruchat S-M, Bouchard L, Hivert M-F (2014) Early Infant Nutrition and Metabolic Programming: What Are the Potential Molecular Mechanisms? Current Nutrition Reports 3(3):281-288. http://doi.org/10.1007/s13668-014-0088-0

48. Santangeli S, Consales C, Pacchierotti F, Habibi H, Carnevali O (2019) Transgenerational effects of BPA on female reproduction. Sci Total Environ 685:1294-1305. http://doi.org/10.1016/j.scitotenv.2019.06.029

49. Srinivasan M, Laychock SG, Hill DJ, Patel MS (2003) J. E. B., \& Medicine. Neonatal Nutrition: Metabolic Programming of Pancreatic Islets and Obesity1. 228(1), 15-23

50. Srinivasan M, Mitrani P, Sadhanandan G, Dodds C, Shbeir-EIDika S, Thamotharan S, Patel MS (2008) A high-carbohydrate diet in the immediate postnatal life of rats induces adaptations predisposing to adult-onset obesity. J J o e 197(3):565-574

51. Stone DAJ (2003) Dietary Carbohydrate Utilization by Fish. Rev Fish Sci 11(4):337-369. http://doi.org/10.1080/10641260390260884

52. Valera A, Robinat A, Pelegrin M, Bosch F (1994) Transgenic Mice Overexpressing Phosphoenolpyruvate Carboxykinase Develop Non-Insulin-Dependent Diabetes Mellitus. Proc Natl Acad Sci USA 91:9151-9154. http://doi.org/10.1073/pnas.91.19.9151

53. Wei Y, Yang C, Wei Y-P, Zhao Z-A, Hou Y, Schatten H, Sun Q-Y (2014) Paternally induced transgenerational inheritance of susceptibility to diabetes in mammals. Proc Natl Acad Sci USA 111. http://doi.org/10.1073/pnas.1321195111

54. Wilkinson MF (2015) Evidence that DNA methylation engenders dynamic gene regulation. Proc Natl Acad Sci USA 112:E2116. http://doi.org/10.1073/pnas.1502195112

55. Wilson RP (1994) Utilization of dietary carbohydrate by fish. Aquaculture 124(1):67-80. http://doi.org/https://doi.org/10.1016/0044-8486(94)90363-8

56. Wilson RP (2003) Utilization of dietary carbohydrate by fish. Aquaculture 124:67-80. http://doi.org/10.1016/0044-8486(94)90363-8

57. Zambonino-Infante JL, Panserat S, Servili A, Mouchel O, Madec L, Mazurais D (2019) Nutritional programming by dietary carbohydrates in European sea bass larvae: Not always what expected at juvenile stage. Aquaculture 501:441-447. http://doi.org/https://doi.org/10.1016/j.aquaculture.2018.11.056

58. Zheng J, Xiao X, Zhang Q, Yu M (2014) DNA methylation: the pivotal interaction between early-life nutrition and glucose metabolism in later life. $\mathrm{Br} J$ Nutr 112(11):1850-1857. http://doi.org/10.1017/s0007114514002827

\section{Tables}

Table1 Ingredient formulation and proximate chemical composition of the experimental diets 


\begin{tabular}{|llll|}
\hline Diets & Control diet & $\begin{array}{l}\text { High-carbohydrate } \\
(\mathrm{HC}) \text { diet }\end{array}$ & $\begin{array}{l}\text { High-carbohydrate stimulus } \\
(\mathrm{HS}) \text { diet }\end{array}$ \\
\hline Ingredient formulation (\%) & & & \\
\hline Casein & 25 & 25 & 20 \\
\hline Fishmeal & 32 & 32 & 12 \\
\hline Fishoil & 6 & 6 & 6 \\
\hline Vitamin premix ${ }^{1}$ & 1 & 1 & 1 \\
\hline Mineral premix & & 1 & 1 \\
\hline Pre-gelatinized Starch & 1 & 35 & 60 \\
\hline Microcrystalline cellulose & 17 & 0 & 0 \\
\hline Chemical composition & & & 95.72 \\
\hline Dry matter (DM) (\%) & 93.60 & 93.77 & 25.84 \\
\hline Crude protein (\% DM) & 53.35 & 43.40 & 7.19 \\
\hline Crude fat (\% DM) & 8.87 & 8.90 & 13.31 \\
\hline Ash (\%DM) & 15.09 & 12.34 & 53.66 \\
\hline Carbohydrate & & 35.36 & \\
\hline
\end{tabular}

${ }^{1}$ Vitamin premix (mg/kg diet): vitamin D3, 0.05; vitamin A1, 6.9; vitamin $\mathrm{K} 3,25$; vitamin $\mathrm{E}, 100$; vitamin $\mathrm{B} 1$ (thiamin), 30; vitamin B2 (riboflavin), 30; vitamin B6, 20; vitamin B12, 0.1; nicotinic acid, 200; folic acid, 15; ascorbic acid, 1000; inositol, 500; vitamin H, 3; pantothenic acid calcium, 100 (Gao Long Dietary Company).

${ }^{2}$ Mineral premix (mg/kg diet): $\mathrm{CoSO}_{4} \cdot \mathrm{H}_{2} \mathrm{O}, 0.65 ; \mathrm{CuSO}_{4} \cdot 5 \mathrm{H}_{2} \mathrm{O}, 9 ; \mathrm{FeSO}_{4} \cdot 7 \mathrm{H}_{2} \mathrm{O}, 8.34 ; \mathrm{KI}, 0.5 ; \mathrm{MnSO}_{4} \cdot \mathrm{H}_{2} \mathrm{O}$, 22.85; $\mathrm{Na}_{2} \mathrm{SeO}_{3}, 0.01 ; \mathrm{ZnSO}_{4} .7 \mathrm{H}_{2} \mathrm{O}, 14.3 ; \mathrm{NaCl}, 400 ; \mathrm{CaCO} 3,1860 ; \mathrm{MgSO} 4,240$ (Gao Long Dietary Company).

${ }^{3}$ Carbohydrate $=1-($ crude protein + crude fat + ash $)$.

Table2 Feeding scheme followed in the experiment 


\begin{tabular}{|lllll|}
\hline Treatments & First trial period & & Final challenge \\
\cline { 2 - 4 } & $3-5 \mathrm{dph}$ & $6-10 \mathrm{dph}$ & 11 dph-15th week & 16th week \\
\hline Control group & Control diet & Control diet & Control diet & HC \\
\hline FF & HS & Control diet & Control diet & HC \\
\hline YE & Control diet & HS & Control diet & HC \\
\hline & First trial period (3 dpf-15th week) & Final challenge (16th week) \\
\hline Control group (F1) & Control diet & & HC & \\
\hline FF (F1) & Control diet & HC & \\
\hline YE (F1) & Control diet & HC & \\
\hline
\end{tabular}

Abbreviations: dph, days post-hatching; FF, fish fed with HS from the first-feeding stage to the end of the yolk-sac larval stage; YE, fish fed with HS after yolk-sac exhaustion for $5 \mathrm{~d}$. Control group (F1), the next generation of Control group; FF (F1), the next generation of FF group; YE (F1), the next generation of YE group.

Table 3. List of primers used in the quantitative real-time PCR 


\begin{tabular}{|c|c|c|}
\hline Genes & Primer sequences & Accession no. \\
\hline \multirow[t]{2}{*}{$\beta$-actin } & F: ACAGAGAGAAGATGACACAGATCATG & \multirow[t]{2}{*}{ NM_131031 } \\
\hline & R: AGTCCATCACAATACCAGTAGTACG & \\
\hline \multirow[t]{2}{*}{ gck } & F: TGAGGATGAAGAGCGAGGC & \multirow[t]{2}{*}{ BC122359 } \\
\hline & R:AGAGAAGGTGAATCCCAGTG & \\
\hline \multirow[t]{2}{*}{ pfkla } & F: AGGTATGAACGCAGCCATCC & \multirow[t]{2}{*}{ XM_693543.8 } \\
\hline & R: TGCCAATCACTGTTCCTCCC & \\
\hline \multirow[t]{2}{*}{$p f k l b$} & F: TTTGAGCACAGGATGCCGAA & \multirow[t]{2}{*}{ NM_001328389.1 } \\
\hline & R: TCGATGCTAAGGGTTCGACG & \\
\hline \multirow[t]{2}{*}{$p k$} & F: AGAAACAGCCAAAGGACA & \multirow[t]{2}{*}{ BC152219 } \\
\hline & R: ACGAGGACGATAACGAGA & \\
\hline \multirow[t]{2}{*}{ fbp 1a } & F: CATCTGTATGGGATTGCTGG & \multirow[t]{2}{*}{ NM_199942 } \\
\hline & R: TTACCCCGTCTATCTGGCTC & \\
\hline \multirow[t]{2}{*}{$f b p 1 b$} & F: GAGTCCCAAGGGCAAGCTAA & \multirow[t]{2}{*}{ NM_213132.1 } \\
\hline & R: TACAGGAACCCTCTGGTGGA & \\
\hline \multirow[t]{2}{*}{ pck1 } & F: ATCACGCATCGCTAAAGAGG & \multirow[t]{2}{*}{ NM_214751.1 } \\
\hline & R: CCGCTGCGAAATACTTCTTC & \\
\hline
\end{tabular}

Abbreviations: gck, glucokinase; $p f k l a$, phosphofructokinase, liver a; $p f k l b$, phosphofructokinase, liver b; $g k$, pyruvate kinase; fbp1a, fructose-1,6-bisphosphatase 1a; fbp 1b, fructose-1,6-bisphosphatase 1b; $p c k 1$, phosphoenolpyruvate carboxykinase 1

Table 4. List of primers used in the BSP amplified and DNA methylation analysis

\begin{tabular}{|c|c|c|}
\hline Prime name & Sequence $\left(5^{\prime}-3^{\prime}\right)$ & $\operatorname{Tm}\left({ }^{\circ} \mathrm{C}\right)$ \\
\hline \multirow[t]{2}{*}{ ZF-BSP-pck1 } & F: GAATGAATGAATGATTTAGTTTGATTT & \multirow[t]{2}{*}{48} \\
\hline & R: AAACATTAAACTATAATTTTTAAAAAAACAC & \\
\hline
\end{tabular}

Table 5. Growth performance of zebrafish during the early stages 


\begin{tabular}{|lllll|}
\hline \multicolumn{3}{|c|}{ Control group } & \multicolumn{2}{c|}{ Experimental group } \\
\hline Treatments & Mean & se & Mean & se \\
\hline FF & & & & \\
\hline Wet weight $^{1}(\mathrm{mg})$ & $0.78^{\mathrm{a}}$ & 0.04 & $0.94^{\mathrm{b}}$ & 0.04 \\
\hline Total length $(\mathrm{mm})$ & 4.46 & 0.05 & 4.35 & 0.06 \\
\hline YE & & & & \\
\hline Wet weight $(\mathrm{mg})$ & $1.34^{\mathrm{a}}$ & 0.02 & $1.19^{\mathrm{b}}$ & 0.03 \\
\hline Total length $(\mathrm{mm})$ & 5.04 & 0.06 & 4.87 & 0.05 \\
\hline
\end{tabular}

Control group, fish fed with control diet; FF, fish fed with HS from the first-feeding stage to the end of the yolk-sac larval stage; YE, fish fed with HS after yolk-sac exhaustion for $5 \mathrm{~d}$.

a,b Mean values within a row with unlike superscript letters were significantly different $(P<0.05)$

${ }^{1}$ Due to small size, the mean weight was used.

Table 6. Growth performance and plasma glucose level of the F0 adult zebrafish

\begin{tabular}{|llllllll|}
\hline & \multicolumn{2}{l}{ Treatments } & & & & \\
& \multicolumn{2}{c}{ Control group } & FF & \multicolumn{3}{l|}{ YE } & \\
& Mean & se & Mean & se & Mean & se \\
\hline Body weight $(\mathrm{mg})$ & 370.40 & 14.46 & 343.60 & 33.20 & 375.30 & 28.02 \\
\hline Body length $(\mathrm{mm})$ & 32.12 & 0.74 & 29.62 & 0.76 & 29.95 & 0.71 \\
\hline BC glucose levels $(\mathrm{mM})^{1}$ & 3.23 & 0.18 & 2.59 & 0.19 & 2.84 & 0.12 \\
\hline AC glucose levels $(\mathrm{mM})^{2}$ & $4.26^{\mathrm{a}}$ & 0.16 & $3.45^{\mathrm{b}}$ & 0.22 & $3.51^{\mathrm{b}}$ & 0.11 \\
\hline
\end{tabular}

Control group, fish fed with control diet; FF, fish fed with HS from the first-feeding stage to the end of the yolk-sac larval stage; YE, fish fed with HS after yolk-sac exhaustion for $5 \mathrm{~d}$.

${ }^{1} \mathrm{BC}$ glucose level, the glucose level before $\mathrm{HC}$ challenge.

${ }^{2} \mathrm{AC}$ glucose level, the glucose level after $\mathrm{HC}$ challenge

a,b Mean values within a row with unlike superscript letters were significantly different $(P<0.05)$. 
Table 7. Growth performance and plasma glucose levels of the F1 adult zebrafish

\begin{tabular}{|c|c|c|c|c|c|c|}
\hline & \multicolumn{6}{|c|}{ Treatments } \\
\hline & \multicolumn{2}{|c|}{ Control group (F1) } & \multicolumn{2}{|l|}{$\mathrm{FF}(\mathrm{F} 1)$} & \multicolumn{2}{|c|}{ YE (F1) } \\
\hline & Mean & se & Mean & se & Mean & se \\
\hline Body weight (mg) & 388.80 & 9.96 & 401.43 & 7.35 & 398.03 & 11.65 \\
\hline Body length (mm) & 32.51 & 0.75 & 33.22 & 0.47 & 34.25 & 0.63 \\
\hline BC Glucose levels $(\mathrm{mM})^{1}$ & 3.33 & 0.11 & 3.14 & 0.16 & 3.19 & 0.02 \\
\hline AC Glucose levels $(\mathrm{mM})^{2}$ & $4.67^{\mathrm{a}}$ & 0.15 & $3.78^{\mathrm{b}}$ & 0.26 & $4.50^{\mathrm{a}}$ & 0.21 \\
\hline
\end{tabular}

Control group (F1), the next generation of the Control group; FF (F1), the next generation of the FF group; YE (F1), the next generation of YE group.

${ }^{1} \mathrm{BC}$ glucose levels, the glucose levels before $\mathrm{HC}$ challenge.

${ }^{2} \mathrm{AC}$ glucose levels, the glucose levels after $\mathrm{HC}$ challenge

a,b Mean values within a row with unlike superscript letters were significantly different $(P<0.05)$.

\section{Figures}



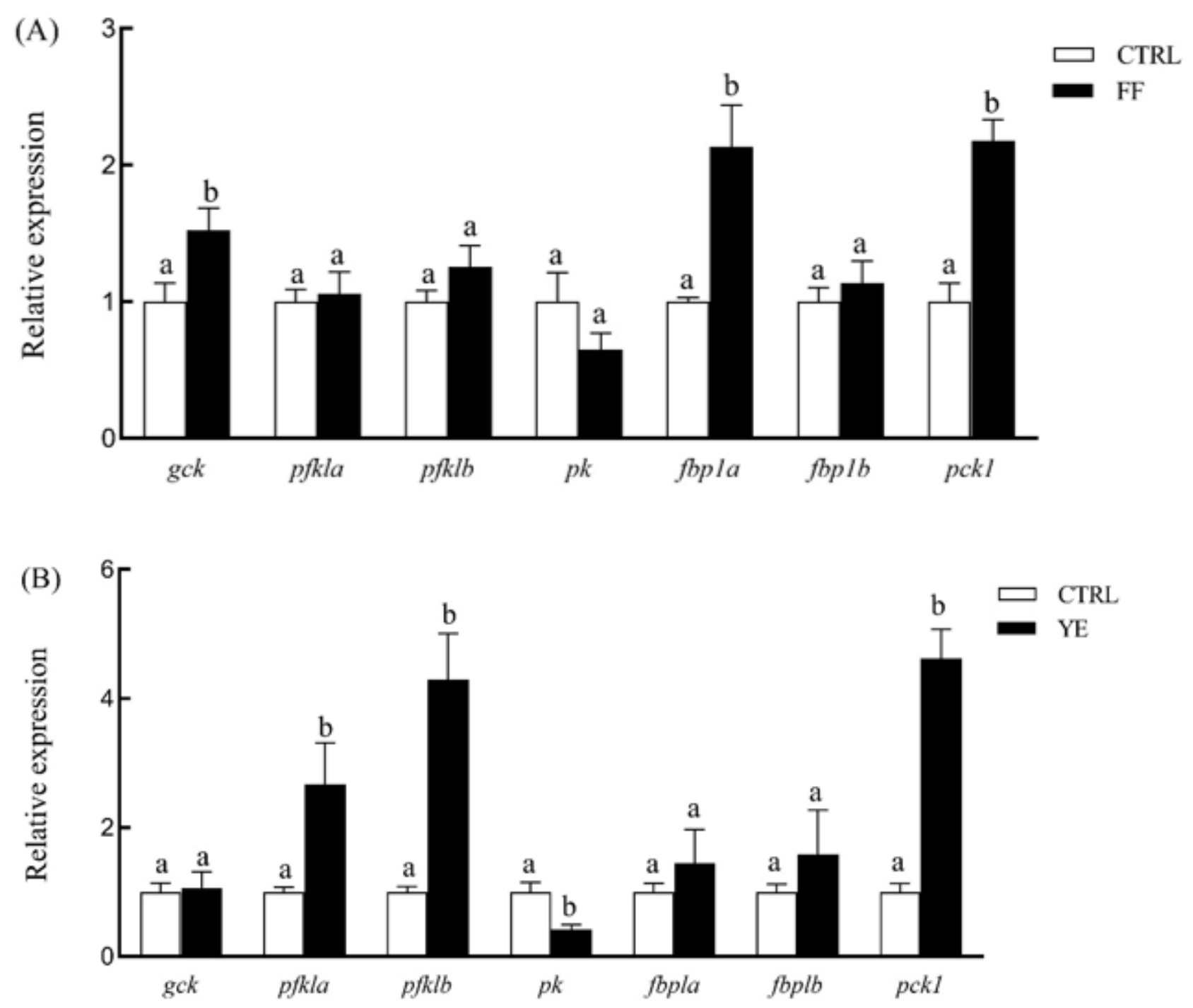

Figure 1

Expression of seven key genes in zebrafish larvae fed with HS at different stages. gk, glucokinase; $p f k l a$, phosphofructokinase, liver a; $p f k l b$, phosphofructokinase, liver b; $p k$, pyruvate kinase; fbp1a, fructose-1,6bisphosphatase 1a; fbp1b, fructose-1,6-bisphosphatase 1b; $p c k 1$, phosphoenolpyruvate carboxykinase 1 . (A) CTRL, fish fed with control diet ; FF, fish fed with HS from the first-feeding stage to the end of the yolksac larval stage; (B) CTRL, fish fed with control diet; YE, fish fed with HS after yolk-sac exhaustion for $5 \mathrm{~d}$. Different letters in the bar graph indicate significant differences $(P<0.05, \mathrm{n}=6)$. 


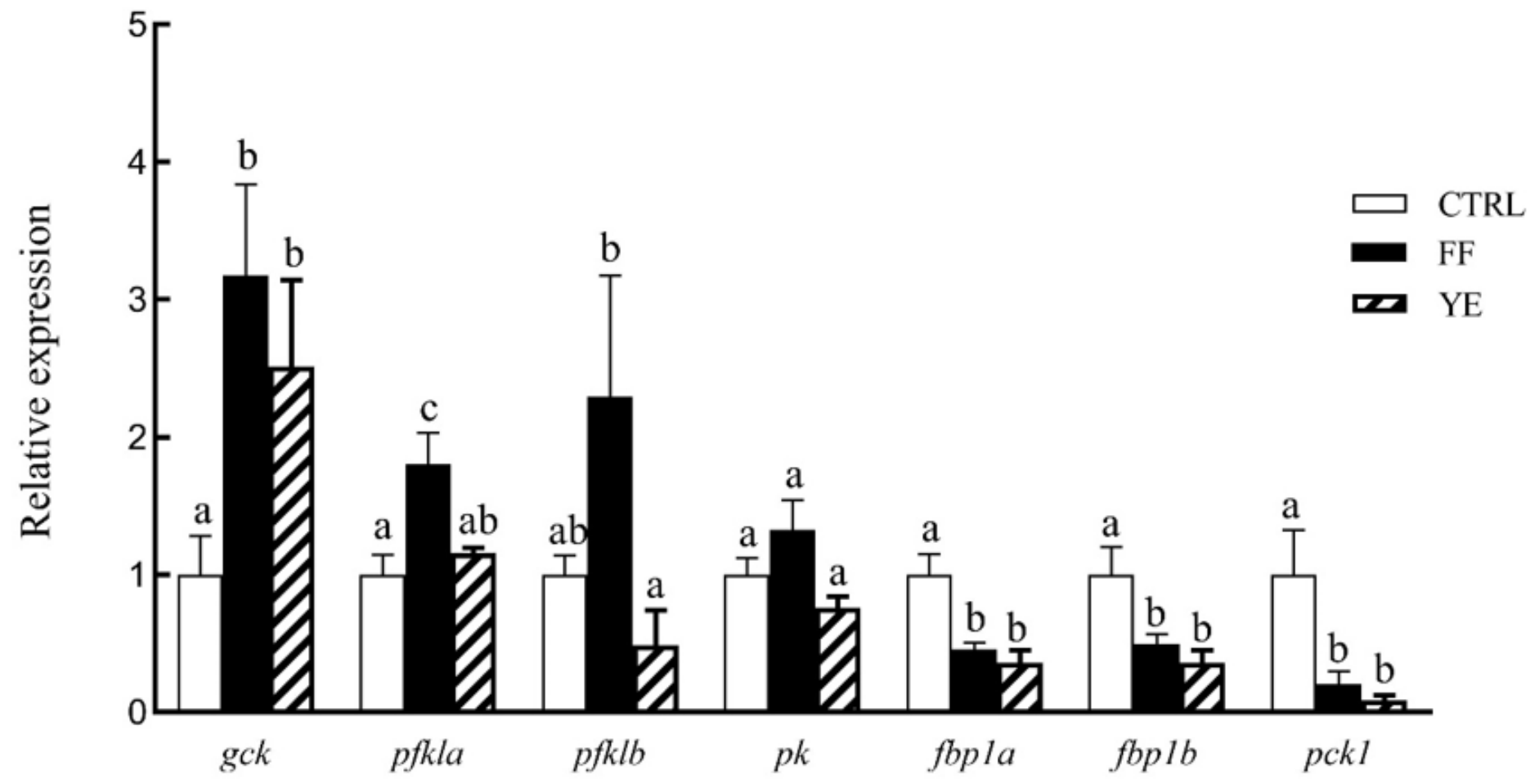

Figure 2

Long-term effect of early high-carbohydrate treatment on hepatic gene expression in adult zebrafish (one week HC challenge). $g k$, glucokinase; $p f k l a$, phosphofructokinase, liver a; $p f k l b$, phosphofructokinase, liver b; $p k$, pyruvate kinase; fbp1a, fructose-1,6-bisphosphatase 1a; fbp 1b, fructose-1,6-bisphosphatase 1b; pck1, phosphoenolpyruvate carboxykinase 1. CTRL, fish fed with control diet; FF, fish fed with HS the from the first-feeding stage to the end of the yolk-sac larval stage; YE, fish fed with HS after yolk-sac exhaustion for $5 \mathrm{~d}$. Different letters in the bar graph indicate significant differences $(P<0.05, n=6)$. 


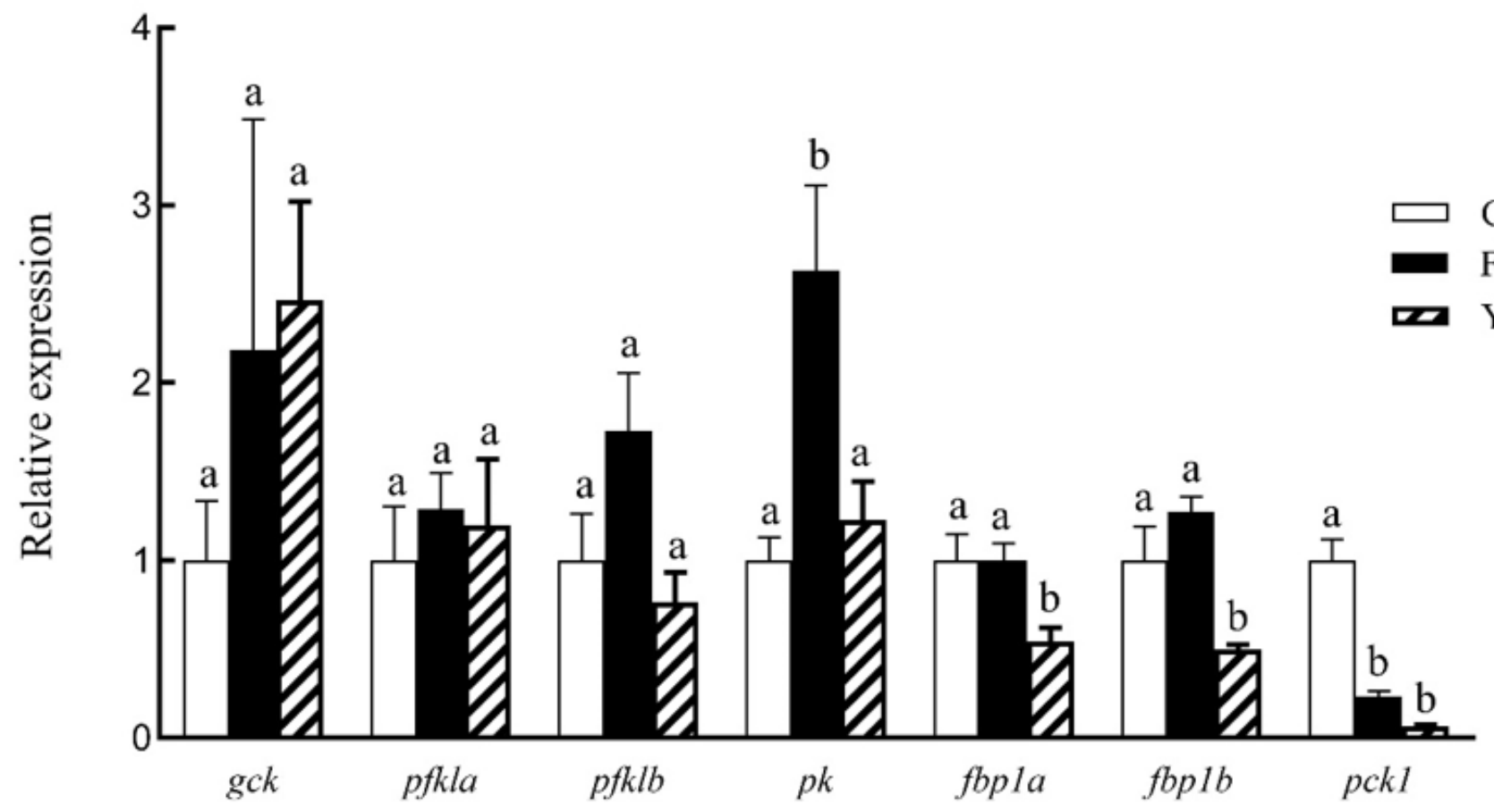

Figure 3

Effects of early high-carbohydrate treatment on hepatic gene expression in adult zebrafish of F1 generation (one week HC challenge). gck, glucokinase; $p f k l a$, phosphofructokinase, liver a; $p f k l b$, phosphofructokinase, liver b; $p k$, pyruvate kinase; fbp $1 a$, fructose-1,6-bisphosphatase $1 \mathrm{a} ; f b p 1 b$, fructose1,6-bisphosphatase 1b; pck1, phosphoenolpyruvate carboxykinase 1. CTRL (F1), the next generation of the control group ; FF (F1), the next generation of the FF group; YE (F1), the next generation of the YE group. Different letters in the bar graph indicate significant differences $(P<0.05, \mathrm{n}=6)$. 


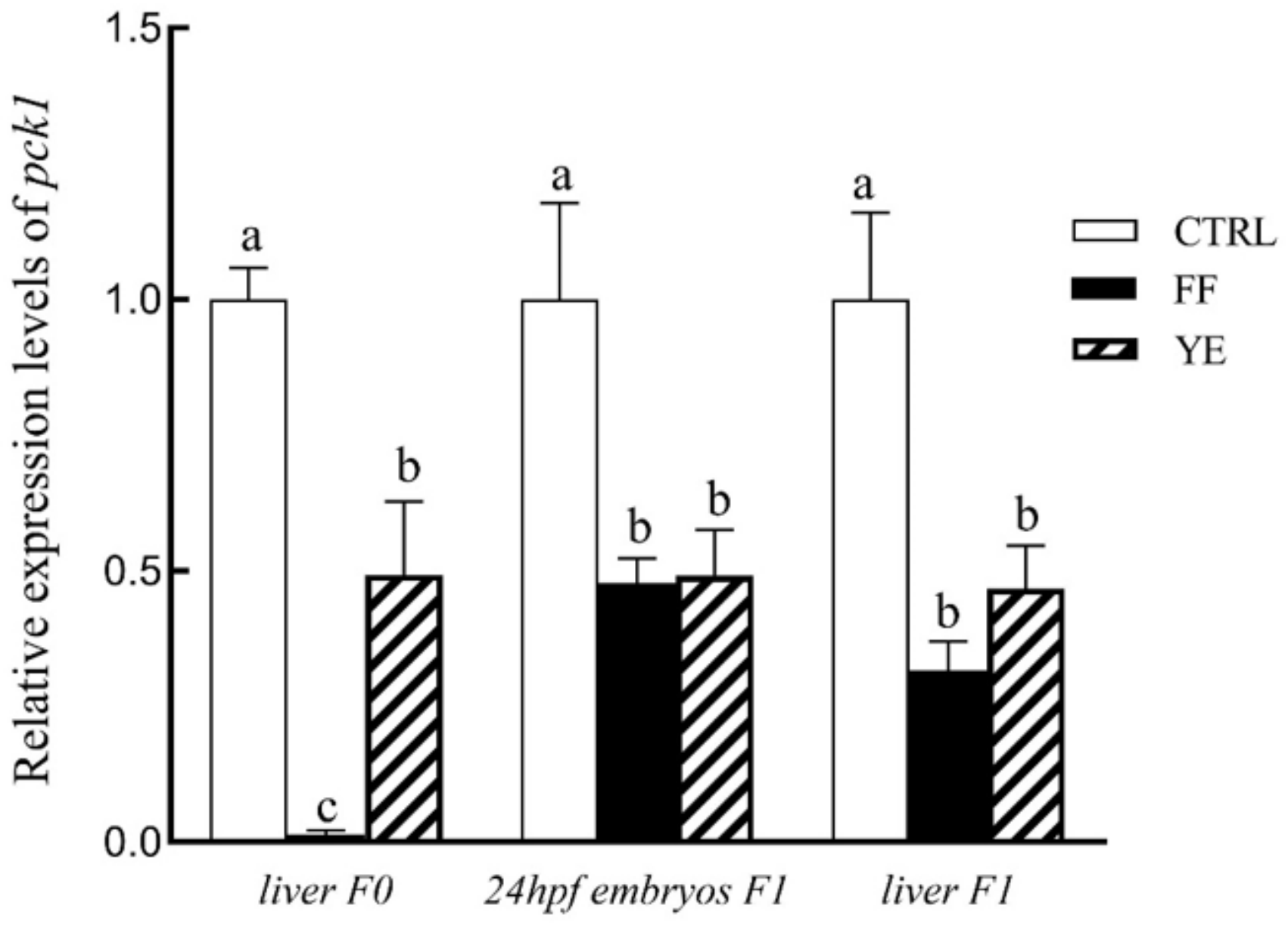

Figure 4

The $p c k 1$ expression levels in $\mathrm{FF}, \mathrm{YE}$, control group in F0 and F1. pck1, phosphoenolpyruvate carboxykinase 1. Liver F0, the liver of F0 adult zebrafish; 24 hpf embryos F1, the F1 embryos of 24 hours post fertilization; Liver F1, the liver of F1 adult zebrafish. CTRL, fish fed the control diet; FF, fish fed with HS from the first-feeding stage to the end of the yolk-sac larval stage; YE, fish fed with HS after yolk-sac exhaustion for $5 \mathrm{~d}$. Different letters in the bar graph indicate significant differences $(P<0.05, n=6)$. 


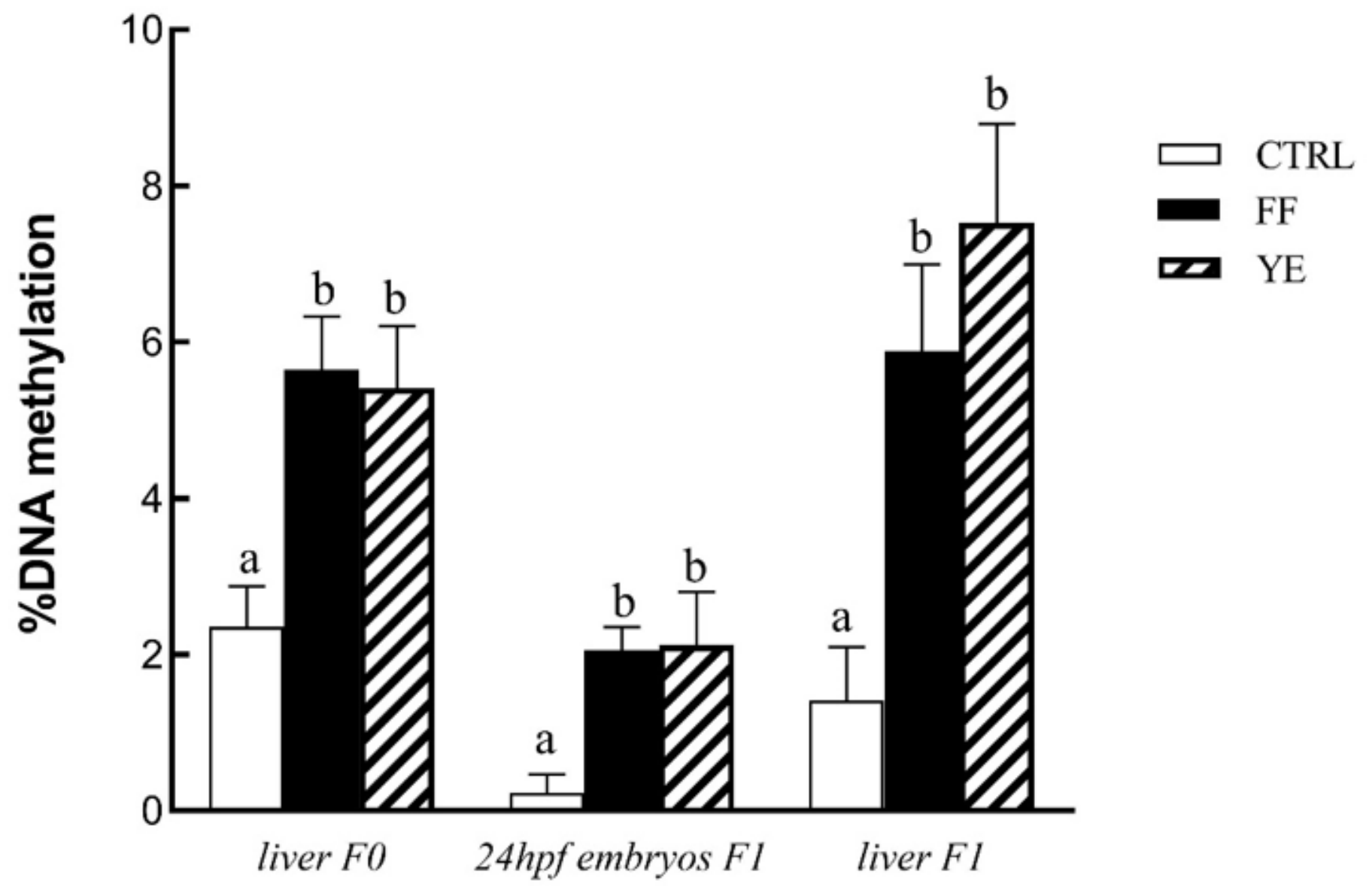

Figure 5

Gene-specific DNA methylation in the promoter region of pck1. $17 \mathrm{CpG}$ sites in the promoter region of the pck 1 gene were analyzed in the liver of F0 adult, 24 hpf embryos F1 and the liver of F1 adult. Data are presented as the mean of the percentage in methylation for the $17 \mathrm{CpG}$ sites analyzed in each groups. Different letters in the bar graph indicate significant differences $(P<0.05, \mathrm{n}=6)$. 